This item was submitted to Loughborough's Research Repository by the author.

Items in Figshare are protected by copyright, with all rights reserved, unless otherwise indicated.

\title{
Braided textile composites for sports protection: Energy absorption and delamination in impact modelling
}

PLEASE CITE THE PUBLISHED VERSION

https://doi.org/10.1016/j.matdes.2017.10.006

\section{PUBLISHER}

(c) Elsevier

VERSION

AM (Accepted Manuscript)

\section{PUBLISHER STATEMENT}

This work is made available according to the conditions of the Creative Commons Attribution-NonCommercialNoDerivatives 4.0 International (CC BY-NC-ND 4.0) licence. Full details of this licence are available at: https://creativecommons.org/licenses/by-nc-nd/4.0/

\section{LICENCE}

CC BY-NC-ND 4.0

\section{REPOSITORY RECORD}

Wang, Chen, Anish Roy, Zhong Chen, and Vadim V. Silberschmidt. 2019. "Braided Textile Composites for Sports Protection: Energy Absorption and Delamination in Impact Modelling". figshare. https://hdl.handle.net/2134/27544. 


\title{
Braided textile composites for sports protection: Energy absorption and delamination in impact modelling
}

\author{
Chen Wang ${ }^{\mathrm{a}, \mathrm{b}, \mathrm{c}}$, Anish Roy ${ }^{\mathrm{b}}$, Zhong Chen ${ }^{\mathrm{a}}$, Vadim V. Silberschmidt ${ }^{\mathrm{b}, *}$ \\ a School of Materials Science and Engineering, Nanyang Technological University, 50 Nanyang Avenue, 639798, Singapore \\ ${ }^{\mathrm{b}}$ School of Mechanical, Electrical and Manufacturing Engineering, Loughborough University, Ashby Road, Loughborough LE113TU, United Kingdom \\ c Institute for Sports Research, Nanyang Technological University, 50 Nanyang Avenue, 639798, Singapore
}

- Dynamic responses of braided compos-ites to low-velocity impacts and inter-face damage are investigated.

- A multi-scale modelling scheme is de-veloped and verified with experiments for a shin-guard structure.

- Load and energy evolution in impacts is assessed using surface- and element-based cohesive zone models.

- The finite-element model with $3 d$ elements provides good prediction for delamination and energy dissipation.

- Inter-yarn debonding is the main energy-absorption mechanism of braided com-posites under low-velocity impact.

A B S T R A C T

Composites reinforced with braided textiles exhibit high structural stability and excellent damage tolerance, making them ideal materials for use in sports-protection equipment. In sports impact scenarios, braided compos-ites need to maintain their structure integrity and dissipate impact energy to protect a human body. Thus, it is crucial to study the dynamic response of a composite structure and its energy-dissipation mechanisms. Here, a multi-scale computational approach was explored to capture main damage modes of a braided textile composite; simulations were supported by experimental verification. A drop-weight test was performed with a spike-shape impactor to imitate real-life sports impact collision scenarios, followed by X-ray computed microtomography to characterize damage morphology of the specimen. The experimental results were compared with analytical models. The extent of delamination was quantified by applying surfaceand element-based cohesive zone models. A ply-level model with three-dimensional continuum and shell elements was employed to explore the effect of through-thickness failure modes on energy absorption of the composite. The propagation mechanism of matrix cracks is also discussed. In addition, with the developed model, impact-attenuation performance of a shin-guard structure was simulated. The presented modelling capability can improve design of braided composite structures for sports and other protective and structural applications.

\footnotetext{
* Corresponding author.

E-mail address: v.silberschmidt@lboro.ac.uk (V.V. Silberschmidt).
} 


\section{Introduction}

Composites reinforced with braided textiles exhibit high structural stability and excellent damage tolerance thanks mostly to yarn interlacing. With their high stiffness-to-weight and strength-toweight ratios, braided composites are attractive materials for aerospace and automotive components as well as sports protective equipment [1-2]. Sports activities always have a potential risk of injury from impacts and collisions. In order to reduce this risk, protective equipment is designed, usually with a rigid outer shell and a soft liner (e.g. helmets and shin guards). Braided textiles composites were considered for the outer shell to improve its protective performance under low-velocity impacts. To enhance material design for such applications, a study of braided composites under impact loads becomes crucial [2]. Specifically for the components in sports-protection applications, energyabsorption capability is of a greater importance in contrast to structural integrity as in other structural applications.

Although extensive experimental and analytical studies demonstrated the materials response, damage morphologies and residual strength of composites subjected to a variety of low-velocity impact conditions [3-7], limited studies have been aimed at elucidating energy-absorption mechanisms of braided composites. In addition, barely visible internal damage (BVID) caused by low-velocity impact condition is difficult to detect experimentally and may often be overlooked with disastrous consequences. Therefore, there is a strong need to develop robust finiteelement (FE) models capable of predicting dynamic behaviour of braided composites, considering multiple damage mechanisms [2-8]. Once successfully developed, the models can then be used to study and design structures under various impact conditions in sports scenarios that are either difficult or time-consuming to reproduce by experimental studies.

Recently, several numerical studies were focused on prediction of an impact response and, in particular, delamination induced in composites during impacts. For this, a virtual crack closure technique (VCCT) and cohesive zone models (CZM) were used widely to model processes at the composite interface. However, the VCCT is known to be sensitive to time increments in simulations and requires an assumption of a pre-existing crack (which may not be physically relevant). In contrast, the CZM combines strength-based criteria used to predict damage initiation with fracture energy criteria to simulate damage propagation, yielding acceptable results with fewer limitations [9]. Generally, the CZM uses surface- and element-based approaches. In the former, the interface is regarded as interaction between two adjoining surfaces, and thickness of the interface is neglected. Long et al. [10] and Qiu et al. [11] successfully developed a cohesive interaction scheme for prediction of initiation and propagation of delamination during impact. Zhang et al. [12] reduced the computation time by using a quasi-static load with a surface-based cohesive contact model available in the ABAQUS FE software package. In the element-based method, COH3D8 cohesive elements (available in ABAQUS) were inserted at the interfaces between composite layers. Using this approach, Feng et al. [13] investigated the influence of simulated intra-laminar damage modes on prediction of interface delamination. Kim et al. [14] studied the effect of delamination damage on performance of a whole structure. Although both approaches are acceptable, there is a lack of systematic studies to compare their advantages and shortcomings.

Modelling schemes based on continuum damage mechanics (CDM) models were adopted in the past few years to represent intra-laminar damage (such as matrix cracking and fibre fracture) developing in laminates under impact loading [15]. Planar CDM degradation models controlled by energy-dissipation constants were implemented in the ABAQUS/Explicit and DYNA3D FE codes for predicting the impact damage resistance of woven composite laminates $[13,16]$. The approach is popular because of its relative simplicity and acceptable results; however, some studies claimed that the normal stress in the throughthickness direction was neglected, therefore 3D stress and strain states with the use of a user-defined subroutine were adopted [17].
Continuum 3D stress elements were applied in these studies instead of shell elements to model composite plies. In summary, a large number of factors affect the impact behaviour of composites, making its numerical modelling a challenge [9-17]. As a result, a universal numerical approach, accounting for the impact load, energy and damage evolution during impact, is currently lacking.

This work aims at investigating a response of braided composite to low-velocity impacts both experimentally and through FE simulation. Capabilities for evaluation and prediction of energy absorption were developed to estimate better protection performance of the material. Macro-scale models of braided textile reinforced composites are presented as a part of multi-scale approach. It is used to study composite fracture and delamination under impact using ABAQUS/Explicit. Specifically, both surface- and element-based cohesive-zone models were analysed. The effect of out-of-plane stress component on the global response of the studied composite during impact was investigated by adopting plane and 3D CDM formulations. The damaged samples were characterized with X-ray micro-topography scanning. The experimental data were compared to results from analytical models and FE simulations, and the main energy dissipation mechanisms of the braided composite were discussed. Finally, as a case study for numerical evaluation of a sports product, the developed FE model was applied to predict the impact-attenuation performance of a shin-guard structure made of a braided-composite shell.

\section{Experimental work}

A braided preform of the studied composite contained carbon fibre tows (AKSAca A-42-12k); a matrix material was Bakelite ${ }^{\circledR}$ EPR-L20 epoxy resin mixed with EPH-960 hardener at a weight ratio of 100:35, and the mixture was then degassed for approximately $30 \mathrm{~min}$. The epoxy resin was injected into the preform employing a vacuumassisted resin-infusion (VARI) method before curing for $24 \mathrm{~h}$ at room temperature followed by $15 \mathrm{~h}$ at $60{ }^{\circ} \mathrm{C}$. The braiding angle in the laminates was $25^{\circ}$ and a fibre volume fraction was about $55 \%$. In sports applications, thickness of an outer shell in protective equipment is usually below $2 \mathrm{~mm}$ to reduce the weight. Hence, in the current work, the plates were prepared with dimensions of $55 \mathrm{~mm} \times 55 \mathrm{~mm} \times 1.6 \mathrm{~mm}$. Each plate consists of two layers of the braided textile.

The drop-weight test programme was carried out with a $9250 \mathrm{HV}$ Instron Dynatup test system, as shown in Fig. 1. A spike-shape impactor was chosen considering real-life conditions of sports impact collisions between football shoes and shin-guards. The impactor has a flat bottom with a radius of approximately $5 \mathrm{~mm}$ (Fig. 1(b)) and a weight of $6.164 \mathrm{~kg}$. The testing machine was equipped with an anti-rebound system to prevent multiple impacts on the tested specimen. The lowvelocity impact tests were carried out according to ASTM Standard D 7136, with different impact energies ( $3 \mathrm{~J}, 6 \mathrm{~J}$ and $9 \mathrm{~J}$ ); this was achieved by varying the initial height of the impactor with a constant mass. The specimens were supported on a pneumatically clamped ring with a $40 \mathrm{~mm}$ internal diameter. The ratio of a diameter of an area of the clamped sample exposed to the impact to the diameter of impactor's bottom was 4 . Magnitudes of time, energy, force, deflection, and velocity were recorded automatically by the system.

All the specimens were inspected post-test with X-ray microcomputed tomography (Micro-CT) measurements using a Metris 160 H-XT XCT system to investigate the extent of the internal damage and delamination. Each scan was conducted at $60 \mathrm{kV}$ and $150 \mu \mathrm{A}$ using a tungsten target, with 2650 radiography projections taken over the $360^{\circ}$ rotation for each specimen at an exposure of $500 \mathrm{~ms}$.

A shin-guard structure consists of a composite shell and an elasticfoam liner. In this study, a flat-shaped specimen was prepared, as illustrated in Fig. 2. The shell was made of the studied $\pm 25^{\circ}$ bi-axial braided composite. The backing layer (PORON® $\mathrm{XRD}^{\mathrm{TM}}$ Extreme Impact Protection) was a type of commercial foam with the thickness of $2 \mathrm{~mm}$. As shown in Fig. 2, the supporting material was made of silicone rubber 


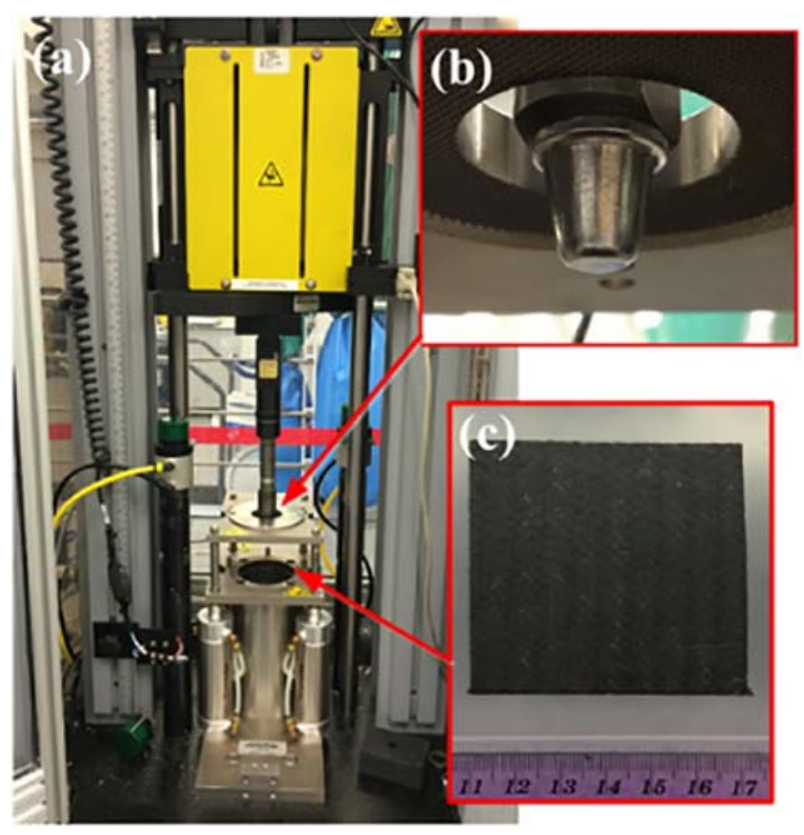

Fig. 1. Drop-weight impact test setup (a) with spike-shape impactor (b) and plate braided composite specimen (c).

(GLOBAL RTV 66, Singapore) with the hardness of 60 durometer (Shore A) to imitate a human body. An impact-attenuation test was carried out using a twin-wire guided vertical impactor (Cadex Inc., Quebec, Canada). The impactor setup included a supporting anvil, a flying arm and a measurement system. The test was designed according to ASTM F355-16 and F1631-95 standards. A hemispheric impactor with the diameter of $15 \mathrm{~mm}$ was used. The total mass of the moving assembly (the flying arm and the impactor) was $5.468 \mathrm{~kg}$. The test system was calibrated with a $12.7 \mathrm{~mm}$ thick hard rubber Modular Elastomer Pad (MEP). The MEP was then replaced with the mentioned silicone rubber, with the same hardness, as supporting material on a steel anvil, as shown in Fig. 2. Upon impact, an instantaneous acceleration was recorded and an impact velocity was measured; two impact energy levels (4 J and $6 \mathrm{~J}$ ) were tested. Each experiment was repeated three times. The acceleration and load-cell data were recorded every $20 \mathrm{~ms}$. In this test, the normalised acceleration (deceleration) $G$ was defined as a ratio of the magnitude of missile's deceleration during the impact $a$ to the acceleration of gravity $g[18,19]$; hence, $G$ is dimensionless. $G_{\max }$ is the maximum value of $G$, and the impact attenuation factor $\eta$ was calculated with

$\eta=\frac{G_{\max }^{\text {sample }}}{G_{\max }^{M E P}}$

where $G_{\max }^{\text {sample }}$ and $G_{\max }^{M E P}$ are the $G_{\max }$ values of the specimen and of the MEP or equivalent silicone material $[18,19]$.

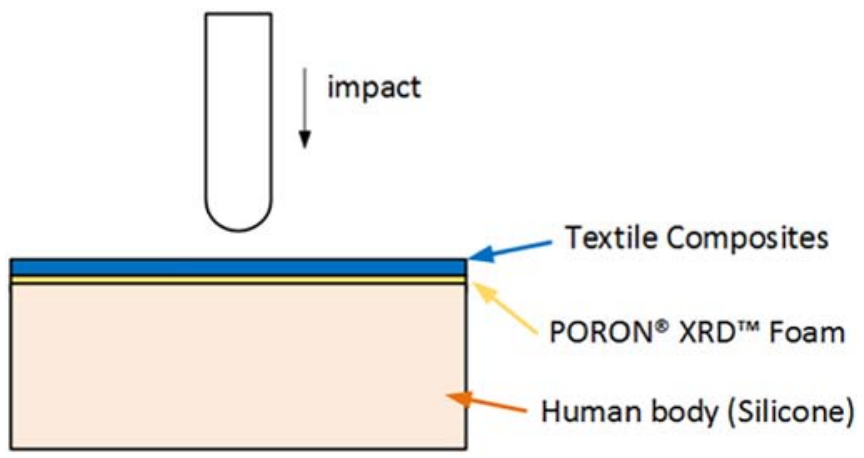

Fig. 2. Illustration of a shin-guard structure specimen in the impact attenuation test.

\section{Finite-element modelling}

The braided composites were modelled employing a multi-scale

modelling approach, with information being passed across lengthscales [20]. Our previous work [21,22], involving a microscopic model, consisting of hexagonally arranged carbon fibre filaments and polymeric matrix, provided the necessary material constants of the fibre tow. Subsequently, a meso-scale unit cell was used to describe the braided architecture of the fibre bundles and to provide material properties for the macro-scale model. Here, a crucial part of the multi-scale strategy, a physically based macroscopic model of braided textile-reinforced composites, is presented.

\subsection{Progressive damage failure analysis}

The Hashin's damage criteria $[23,24]$ are used to model the damage appeared within composites. After damage initiation, the response of the material was computed according to damage evolution law based on stress-displacement behaviours in six failure modes. The values of initiation damage criteria $\varnothing_{I}$ for each type of failure mode $I$ are as follow:

Fibre tensile failure in longitudinal direction $\varnothing_{L}^{t}$ : $\left(\sigma_{1} \geq 0\right)$

$\varnothing_{L}^{t}=\left(\frac{\sigma_{1}}{X_{T}}\right)^{2}+\alpha \frac{\tau_{12}^{2}}{\left(S_{12}\right)^{2}}+\alpha \frac{\tau_{13}^{2}}{\left(S_{13}\right)^{2}}=1$

Fibre compressive failure in longitudinal direction $\varnothing_{L}^{c}:\left(\sigma_{1}<0\right)$

$\varnothing_{L}^{c}=\left(\frac{\sigma_{1}}{X_{C}}\right)^{2}=1$

Matrix tensile failure in transverse direction $\varnothing_{Y}^{t}:\left(\sigma_{2} \geq 0\right)$

$\varnothing_{Y}^{t}=\left(\frac{\sigma_{2}+\alpha \sigma_{3}}{Y_{T}}\right)^{2}+\alpha \frac{\tau_{23}^{2}-\sigma_{2} \sigma_{3}}{\left(S_{23}\right)^{2}}+\frac{\tau_{12}^{2}}{\left(S_{12}\right)^{2}}+\alpha \frac{\tau_{13}^{2}}{\left(S_{13}\right)^{2}}=1$

Matrix compressive failure in transverse direction $\varnothing_{Y}^{c}:\left(\sigma_{2}<0\right)$

$$
\begin{aligned}
\varnothing_{Y}^{c}= & {\left[\left(\frac{Y_{C}}{2 S_{23}}\right)^{2}-1\right] \frac{\sigma_{2}+\alpha \sigma_{3}}{Y_{C}}+\left(\frac{\sigma_{2}+\alpha \sigma_{3}}{2 S_{23}}\right)^{2}+\alpha \frac{\tau_{23}^{2}-\sigma_{2} \sigma_{3}}{\left(S_{23}\right)^{2}} } \\
& +\frac{\tau_{12}^{2}}{\left(S_{12}\right)^{2}}+\alpha \frac{\tau_{13}^{2}}{\left(S_{13}\right)^{2}}=1
\end{aligned}
$$

Matrix tensile failure in thickness direction $\varnothing_{Z}^{t}:\left(\sigma_{3} \geq 0\right)$

$\varnothing_{Z}^{t}=\left(\frac{\sigma_{2}+\sigma_{3}}{Z_{T}}\right)^{2}+\frac{\tau_{23}^{2}-\sigma_{2} \sigma_{3}}{\left(S_{23}\right)^{2}}+\frac{\tau_{12}^{2}}{\left(S_{12}\right)^{2}}+\frac{\tau_{13}^{2}}{\left(S_{13}\right)^{2}}=1$

Matrix compressive failure in thickness direction $\varnothing_{Z}^{c}:\left(\sigma_{3}<0\right)$

$$
\begin{aligned}
\varnothing_{Z}^{c}= & {\left[\left(\frac{Z_{C}}{2 S_{23}}\right)^{2}-1\right] \frac{\sigma_{2}+\sigma_{3}}{Z_{C}}+\left(\frac{\sigma_{2}+\sigma_{3}}{2 S_{23}}\right)^{2}+\frac{\tau_{23}^{2}-\sigma_{2} \sigma_{3}}{\left(S_{23}\right)^{2}}+\frac{\tau_{12}^{2}}{\left(S_{12}\right)^{2}} } \\
& +\frac{\tau_{13}^{2}}{\left(S_{13}\right)^{2}}=1
\end{aligned}
$$

In Eqs. (2)-(7), $X_{T}, Y_{T}$ and $Z_{T}$ denote tensile strengths in the longitudinal $(X)$, transverse $(Y)$ and through-thickness $(Z)$ direction of braided composite, respectively. $X_{C}, Y_{C}$ and $Z_{C}$ are compressive strengths in the $X$, $Y$ and $Z$ direction of the composite, respectively. In indices of stress and strain components, 1,2 and 3 directions are used to described $X, Y$ and $Z$, respectively. Hence, $S_{12}, S_{13}$ and $S_{23}$ signify in-plane and two out-ofplane shear strengths, respectively. The effective normal and shear stress component are denoted by $\sigma_{i}$ and $\tau_{i j}(i, j=1,2,3 ; i \neq j)$, respectively. A plane-stress factor in each mode is represented with $\alpha$. When the 
Table 1

Equivalent displacements and stresses corresponding to different failure modes.

\begin{tabular}{|c|c|c|}
\hline Failure mode $I$ & Equivalent displacement & Equivalent stress \\
\hline$L_{\mathrm{t}}, \sigma_{1} \geq 0$ & $X_{e q}^{L t}=l \sqrt{\varepsilon_{11}^{2}+\varepsilon_{12}^{2}+\alpha \varepsilon_{31}^{2}}$ & $l\left(\left\langle\sigma_{11}\right\rangle\left\langle\varepsilon_{11}\right\rangle+\sigma_{12} \varepsilon_{12}+\alpha \sigma_{13} \varepsilon_{13}\right) / X_{e q}^{L t}$ \\
\hline $\begin{array}{l}L_{\mathrm{c}}, \sigma_{1}<0 \\
Y_{\mathrm{t}}, \sigma_{2} \geq 0\end{array}$ & $\begin{array}{l}X_{e q}^{L c}=l\left\langle-\varepsilon_{11}\right\rangle \\
X_{e q}^{Y t}=l \sqrt{\varepsilon_{22}^{2}+\varepsilon_{12}^{2}+\alpha \varepsilon_{23}^{2}}\end{array}$ & $\begin{array}{l}l\left(\left\langle-\sigma_{11}\right\rangle\left\langle-\varepsilon_{11}\right\rangle\right) / X_{e q}^{L c} \\
l\left(\left\langle\sigma_{22}\right\rangle\left\langle\varepsilon_{22}\right\rangle+\sigma_{12} \varepsilon_{12}+\alpha \sigma_{23} \varepsilon_{23}\right) / X_{e q}^{Y t}\end{array}$ \\
\hline $\begin{array}{l}Y_{\mathrm{c}}, \sigma_{2}<0 \\
Z_{\mathrm{t}}, \sigma_{3} \geq 0\end{array}$ & $\begin{array}{l}X_{e q}^{Y c}=l\left\langle-\varepsilon_{22}\right\rangle \\
X_{e q}^{Z t}=l \sqrt{\varepsilon_{33}^{2}+\varepsilon_{23}^{2}+\varepsilon_{31}^{2}}\end{array}$ & $\begin{array}{l}l\left(\left\langle-\sigma_{22}\right\rangle\left\langle-\varepsilon_{22}\right\rangle\right) / X_{e q}^{Y c} \\
l\left(\left\langle\sigma_{33}\right\rangle\left\langle\varepsilon_{33}\right\rangle+\sigma_{23} \varepsilon_{23}+\sigma_{13} \varepsilon_{13}\right) / X_{e q}^{Z t}\end{array}$ \\
\hline$Z_{\mathrm{c}}, \sigma_{3}<0$ & $X_{e q}^{Z c}=l\left\langle-\varepsilon_{33}\right\rangle$ & $l\left(\left\langle-\sigma_{33}\right\rangle\left\langle-\varepsilon_{33}\right\rangle\right) / X_{e q}^{Z c}$ \\
\hline
\end{tabular}

$\langle x\rangle=(x+|x|) / 2$.

through-thickness stress component is ignored, $\alpha=0$, otherwise, in a three-dimensional case, $\alpha=1$.

For undamaged and elastic orthotropic composite materials, the stress-strain relationship can be written as

$$
\left\{\begin{array}{l}
\sigma_{11} \\
\sigma_{22} \\
\sigma_{33} \\
\tau_{12} \\
\tau_{23} \\
\tau_{13}
\end{array}\right\}=\left[\begin{array}{cccccc}
C_{11} & C_{12} & C_{13} & 0 & 0 & 0 \\
C_{21} & C_{22} & C_{23} & 0 & 0 & 0 \\
C_{31} & C_{32} & C_{33} & 0 & 0 & 0 \\
& & & C_{44} & 0 & 0 \\
& \text { sym } & & & C_{55} & 0 \\
& & & & & C_{66}
\end{array}\right]\left\{\begin{array}{l}
\varepsilon_{11} \\
\varepsilon_{22} \\
\varepsilon_{33} \\
\gamma_{12} \\
\gamma_{23} \\
\gamma_{13}
\end{array}\right\},
$$

where $\sigma_{i j}$ and $\tau_{i j}$ are normal and shear stresses, $\varepsilon_{i j}$ and $\gamma_{i j}$ are normal and shear strains, $C_{i j}$ are stiffness coefficients. According to continuum damage mechanics (CDM) in a finite-element (FE) method, the damage was considered continuously distributed over finite element, and the ply damage models assumed that when the values in the initiation damage criteria $\varnothing_{I}$ was equal to unity, the local stiffness of material $C_{i j}$ degraded. When the constituents of material failed in an element, it dissipated energy equal to its elastic energy. According to Lapczyk and Miami's approach $[24,26]$, a characteristic element length was introduced to the expression to solve a mesh-dependence problem. The equivalent displacement at failure point $X_{e q}^{f}$ is defined as follows:

$X_{e q}^{f}=\varepsilon_{l f} l$

where $l$ is the characteristic length of element and $\varepsilon_{I f}$ is the failure equivalent strain of failure mode $I$. Thus, the degradation of stiffness tensors was characterized by a damage matrix, $\boldsymbol{C}(\boldsymbol{D})$, defined by internal damage variables $d_{I}$ associated to different failure modes I [25]. The damage variable of each failure mode is expressed by the following equivalent displacement:

$d_{I}=\frac{X_{e q}^{I f}\left(X_{e q}^{I}-X_{e q}^{I i}\right)}{X_{e q}^{I}\left(X_{e q}^{I f}-X_{e q}^{I i}\right)}(I=L t, L c, Y t, Y c, Z t, Z c)$.

In Eq. (10), $X^{l i}{ }_{e q}$ and $X^{l f}{ }_{e q}$ are the initiation and full damage equivalent displacement of failure mode $I$, respectively. $X^{I i}{ }_{e q}$ and $X^{I f}{ }_{e q}$ can be calculated with the following equations [27]:

$X_{e q}^{l i}=\frac{X_{e q}^{I}}{\sqrt{\varnothing_{I}}}$,

$X_{e q}^{I f}=\frac{2 G_{I}}{\sigma_{e q}^{I i}}$.

Here, $\varnothing_{I}$ is the value of initiation damage criteria. $G_{I}$ and $\sigma_{e q}^{i i}$ denote the fracture energy density and the initiation damage equivalent stress of failure mode $I$, respectively. The initiation equivalent stress $\sigma_{e q}^{I i}$ can be calculated from the following equation:

$\sigma_{e q}^{I i}=\frac{\sigma_{e q}^{I}}{\sqrt{\varnothing_{I}}}$

In Eqs. (10)-(13), the equivalent stress $\sigma_{e q}^{I}$ and the equivalent displacement $X_{e q}^{I}$ associated to the different failure modes are expressed in Table 1 . The equivalent displacements of initiation damage listed in Table 1 have the similar forms with Eq. (9).

Therefore, the damage evolution equation is associated with the characteristic element length, local strain and fracture energy of the braided-composite constituents. The damaged stiffness matrix $\boldsymbol{C}(\boldsymbol{D})$ can be expressed in a matrix form by using the components of
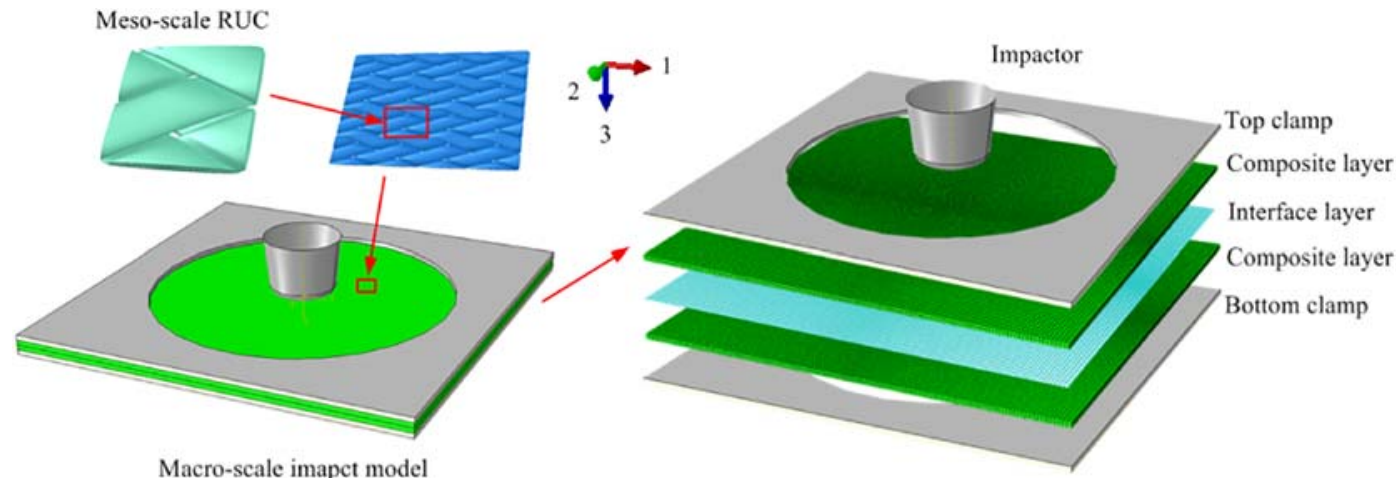

Fig. 3. Drop-weight impact FE model with spike-shape impactor: from meso-scale to macro-scale model. 
undamaged stiffness matrix and the principal values of the damage tensor $D_{I}$ according to the Murakami-Ohno damage model [28]. It can be presented more explicitly as follows:

$C(D)=\left[\begin{array}{cccccc}b_{L}^{2} C_{11} & b_{L} b_{T} C_{12} & b_{L} b_{Z} C_{13} & 0 & 0 & 0 \\ & b_{T}^{2} C_{22} & b_{T} b_{Z} C_{23} & 0 & 0 & 0 \\ & & b_{Z}^{2} C_{33} & 0 & 0 & 0 \\ & \text { sym } & & b_{L T} C_{44} & 0 & 0 \\ & & & & b_{T Z} C_{55} & 0 \\ & & & & & b_{Z L} C_{66}\end{array}\right]$

where $b_{L}=1-D_{L}, b_{T}=1-D_{T}, b_{Z}=1-D_{Z}$,

$$
b_{L T}=\left(\frac{2\left(1-D_{L}\right)\left(1-D_{T}\right)}{2-D_{L}-D_{T}}\right)^{2}, b_{T Z}=\left(\frac{2\left(1-D_{T}\right)\left(1-D_{Z}\right)}{2-D_{T}-D_{Z}}\right)^{2}, b_{Z L}=\left(\frac{2\left(1-D_{Z}\right)\left(1-D_{L}\right)}{2-D_{Z}-D_{L}}\right)^{2},
$$

$C_{i j}(i, j=1,2,3)$ is the component of the undamaged stiffness matrix, $D_{L}=\max \left(d_{L t}, d_{L c}\right), D_{T}=\max \left(d_{T t}, d_{T c}\right)$, and $D_{Z}=\max \left(d_{Z t}, d_{Z c}\right)$.

\subsection{Cohesive-zone model}

Delamination between layers was simulated with the interface cohesive-zone model, defined by a traction-separation constitutive law. This law describes an initial linear-elastic stage until a damageinitiation condition is satisfied, followed by a linear softening phase that simulate progressive de-cohesion of the interface with increasing damage. According to the law, the area under the tractiondisplacement curve represents fracture toughness (the critical energy release rate) for a specific fracture mode [15]. Complete fracture of the interface is assumed to occur when cohesive traction vanishes at the end of the degradation phase. The evolution of damage in simulations was monitored by a damage indicator, ranging from 0 for the undamaged interface to the value of 1 implying complete de-cohesion of the interface. The crack was initiated when a stress-based quadratic interaction criterion was satisfied:

$\left(\frac{t_{n}}{N}\right)^{2}+\left(\frac{t_{s}}{S}\right)^{2}+\left(\frac{t_{t}}{S}\right)^{2}=1$

where $t_{n}, t_{s}$, and $t_{t}$ represent the interface stresses and $N, S$, and $T$ are the interface strengths under mode I (opening), mode II (shear) and mode III (tearing), respectively. The values of $N$ and $S$ were selected in a preliminary calibration phase based on the comparison of experimental results and simulations of interfacial study [14,29].

Damage evolution was defined based on fracture energy, and a linear softening behaviour was utilised. The dependency of fracture energy on mixed fracture modes is expressed by the widely used BenzeggaghKenane formulation [30]:

$G^{C}=G_{n}^{C}+\left(G_{s}^{C}-G_{n}^{C}\right)\left\{\frac{G_{s}^{C}+G_{t}^{C}}{G_{n}^{C}+G_{s}^{C}+G_{t}^{C}}\right\}^{\eta}$,

where $G_{n}, G_{s}$ and $G_{t}$ are the work done by tractions and their conjugate relative displacements corresponding to mode I, II and III, respectively. The power, $\eta$, is a material parameter, selected as 1.45 for a carbonfibre composite [31].

Table 2

Material properties used in FE model.

\begin{tabular}{cl}
\hline Layer properties & $E_{11}=36.37 \mathrm{GPa} ; E_{22}=7.4 \mathrm{GPa}, E_{33}=7.07 \mathrm{GPa} ; \nu_{12}=$ \\
{$[21,22](\mathrm{A}-42 / \mathrm{L} 20)$} & $1.19 ; \nu_{13}=0.026 ; \nu_{23}=0.29 ; G_{12}=16.31 \mathrm{GPa} ; G_{13}=$ \\
& $2.72 \mathrm{GPa} ; G_{23}=2.31 \mathrm{GPa} ; X_{t}=591.57 \mathrm{MPa} ; X_{c}=400$ \\
& $\mathrm{MPa} ; Y_{t}=200 \mathrm{MPa} ; Y_{c}=275 \mathrm{MPa} ; Z_{t}=190 \mathrm{MPa}, Z_{c}=$ \\
& $270 \mathrm{MPa} ; G_{f t}=81.5 \mathrm{~kJ} / \mathrm{m}^{2} ; G_{f c}=100 \mathrm{~kJ} / \mathrm{m}^{2} ; G_{m t}=33$ \\
& $\mathrm{~kJ} / \mathrm{m}^{2} ; G_{m c}=33 \mathrm{~kJ} / \mathrm{m}^{2}$ \\
& $k_{N}=289 \mathrm{GPa} / \mathrm{mm} ; k_{S}=k_{T}=200 \mathrm{GPa} / \mathrm{mm} ; N=58.3$ \\
Layer interface & $\mathrm{MPa} ; S=T=62.3 \mathrm{MPa} ; G_{I c}=350 \mathrm{~J} / \mathrm{m}^{2} ; G_{I I c}=G_{I I I c}=$ \\
properties $[31,32]$ & $1000 \mathrm{~J} / \mathrm{m}^{2}$
\end{tabular}

(a)

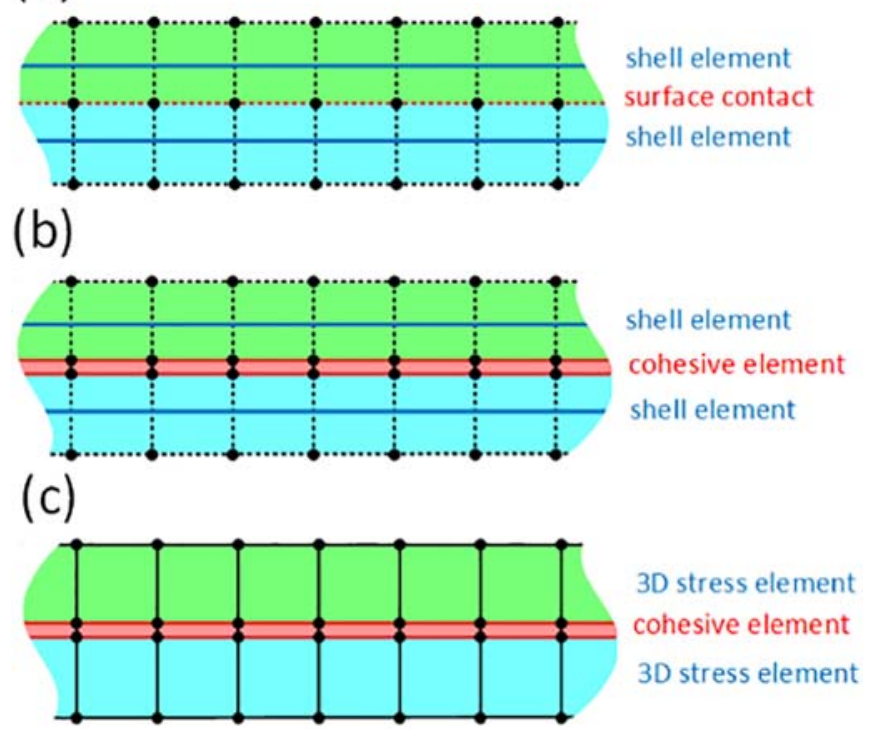

Fig. 4. Three modelling strategies: (a) Surface-based Cohesive Zone (SCZ) with shell elements; (b) Element-based Cohesive Zone (ECZ) with shell elements; (c) ECZ with 3D stress elements (ECZ3D).

\subsection{Drop-weight test model}

The braided composite plate was modelled as a homogeneous material in a macroscopic sense. The circular pneumatic clamps used in the testing machine, shown in Fig. 3, were simulated as rigid bodies (R3D4) with their original geometry. The nodes at the model's periphery were fixed in all directions to mimic the experimental process, where the composite plate was pneumatically clamped. The dimensions of the model were the same as of the employed experimental setup. The spike-shaped impactor was modelled as a rigid body with a lumped mass equal to the mass used in the experimental programme. A general contact algorithm was defined with appropriate contact-pair properties to represent the contact between the impactor and the composite-plate surface. Levels of initial velocity in the vertical direction are prescribed for the impactor, resulting in the corresponding impact energy of 3, 6 and $9 \mathrm{~J}$. The material properties used in this study are listed in Table 2 .

In this study, three numerical modelling techniques were adopted. To explore the appropriate method to model the interface, both surface- and element-based cohesive zone models were applied. In the surface-based cohesive zone (SCZ) model, a cohesive contact algorithm was defined with traction-separation behaviour. In the element-based cohesive zone (ECZ) model, cohesive elements (COH3D8) with thickness of $0.01 \mathrm{~mm}$ were inserted between two plies of the composite. These cohesive zone elements shared the nodes of the adjacent composite layers to moderate the compatibility issue. In SCZ and ECZ models, continuum shell elements (SC8R) were used to model the composite plies so that only plane-stress components were considered in damage mechanics $(\alpha=0$, in Eqs. (2)-(11)). Hashin's 2D failure criteria are available as an inbuilt option in ABAQUS/Explicit. To consider out-of-plane stress components, 3D stress elements (C3D8R) were incorporated in composite layers instead of shell elements in the ECZ model. This model is henceforth referred to as ECZ3D model. Here, the impactinduced damage was modelled by implementing a user-defined 3D damage model ( $\alpha=1$, in Eqs. (2)-(11)) in a VUMAT subroutine of ABAQUS/Explicit. Fig. 4 provides schematics for these three approaches. The interface properties of the cohesive zone model are listed in Table 2. 


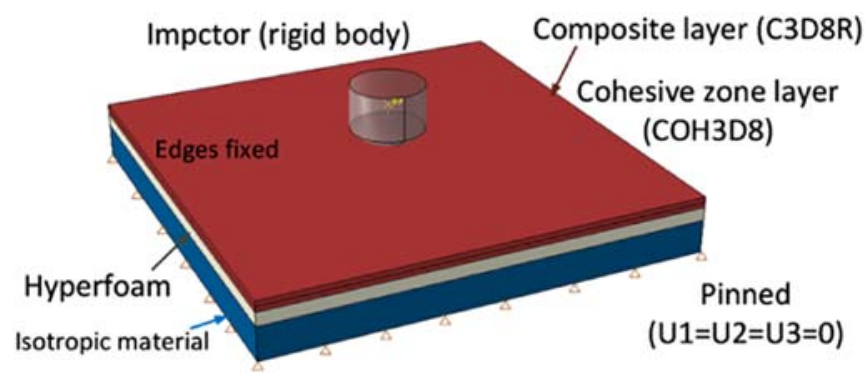

Fig. 5. FE model of impact attenuation test of shin-guard structure.

\subsection{Impact-attenuation model of shin-guard structure}

Finite-element models of the impact-attenuation test were developed with the same multi-scale strategy as that for the drop-weight test. Knowing mechanical behaviours of the $\pm 25^{\circ}$ braided unit cells, the composite shell could be modelled homogeneously with a bonded foam layer. Fig. 5 presents assembling of the parts and boundary conditions for the shin-guard specimen in the impact-attenuation test. The impactor was modelled as a rigid body with a lumped mass equal to the mass used in the experimental programme. Similar to the dropweight cases, the ECZ3D model was applied for the composite layer. The composite plate was clamped so that the nodes at the composite layer's periphery were fixed in all directions. In ABAQUS, the PORON® $\mathrm{XRD}^{\mathrm{TM}}$ foam could be regarded as hyperfoam material with the hyperfoam strain energy potential given by the Ogden function [33]:

$U=\sum_{i=1}^{N} \frac{2 \mu_{i}}{\alpha_{i}^{2}}\left[\lambda_{1}^{\alpha_{i}}+\lambda_{2}^{\alpha_{i}}+\lambda_{3}^{\alpha_{i}}-3+\frac{1}{\beta_{i}}\left(J_{e l}^{-\alpha_{i} \beta_{i}}-1\right)\right]$.

In the Ogden function, $\lambda_{i}$ are the principal deviatoric stretches, $N$ is the order, $J_{e l}$ is the volume ratio, $\mu_{i}$ is the parameter for controlling initial material stiffness and $\alpha_{i}$ is the parameter for controlling strain hardening behaviour. Parameters listed in Table 3 were chosen from the literature for PORON ${ }^{\circledR}$ cushioning foam. The MEP or equivalent supporting silicone rubber can be regarded as isotropic material, with elastic modulus of $2.159 \mathrm{MPa}$ and the Poisson ratio of 0.49 , according to the RTV 66 data sheet. The bottom face of silicone rubber in the FE model was pinned. Levels of initial velocity in the vertical direction were prescribed for the impactor, resulting in the corresponding impact energy of 4 and $6 \mathrm{~J}$.

\section{Analytical model of low-velocity impact}

Analytical modelling is regarded as a simple and effective way to predict bending and stretching deformations of composite materials subjected to low-velocity impacts. With analytical modelling, the type of impact behaviour can be determined [5-7]. The maximum impact load of the composite plate can be predicted with the energy-balance model, which assumes a quasi-static behaviour of a composite structure. According to Abrate's work [5], the energy-balance equation is written as

$\frac{1}{2} M V^{2}=E_{b}+E_{s}+E_{m}+E_{c}$

where $M$ and $V$ are the mass and velocity of the impactor, respectively. For the energy term $E$, the subscript $b, s, m$ and $c$ refer to bending, shear,

Table 3

Material input of PORON® XRD ${ }^{\mathrm{TM}}$ foam $[33,34]$

\begin{tabular}{llllll}
\hline Property & Density $\left(\mathrm{kg} \cdot \mathrm{m}^{-3}\right)$ & $\mu_{1}(\mathrm{GPa})$ & $\alpha_{1}(\mathrm{GPa})$ & $\beta_{1}(\mathrm{GPa})$ & Thickness $(\mathrm{mm})$ \\
\hline Value & 240.28 & 0.620 & 34.46 & 0.04 & 2 \\
\hline
\end{tabular}

membrane and contact components of overall structural deformation. When the maximum deflection is reached, all the kinetic energy is used to deform the composite. Hence, the maximum impact load $P_{\max }$ can be given with contact stiffness $k$, as

$P_{\max }=\left(\frac{5}{4}\right)^{3 / 5}\left[M^{3} V^{6} k^{2}\right]^{1 / 5}$

Spring-mass models were developed by Abrate [5] and Olsson [7], consisting of one spring representing the linear stiffness of the structure $k_{b s}$ and another spring for the nonlinear membrane stiffness $k_{m}$. Therefore, the total load on the composite plate $P_{m b s}$, is composed of the bending and shearing load contribution $P_{b s}$ and the membrane load contribution $P_{m}$, as follows:

$P_{m b s}=P_{b s}+P_{m}$,

$P_{b s}=k_{b s} w_{p}^{3}, \quad P_{m}=k_{m} w_{p} \leq P_{c r}$.

By defining effective plate stiffness $D^{*}$, the critical shear load for the delamination growth can be given as

$P_{c r}=\pi \sqrt{32 D^{*} G_{I I c} /(n+2)}$,

where $G_{\text {IIC }}$ is mode-II interlaminate toughness and $n$ is the number of delaminations. Details of parameter calculation can be found in [5-7]. When calculating $k_{m}$, a clamped immovable boundary condition was used, the same as in the experimental setup.

\section{Results and discussion}

FE predictions and experimental results were compared in terms of global response and delamination damage due to impact. The global responses of the composite were mainly characterized with regard to the maximum impact force, maximum strain energy and total energy absorption.

The impact force diagrams of braided composite under impact loading are shown in Fig. 6. Experimental and simulation results are compared for three impact energy levels. The time to the peak force became smaller with an increase in the impact energy (Fig. 6).

At energy levels of $3 \mathrm{~J}$ and $6 \mathrm{~J}$, the calculated impact-force curves have a reasonably smooth response with an increase of the overall peak-load value. Oscillations on the curves suggest the possibility of progressive failures in the material caused by a decrease in structural stiffness. At an impact energy is $9 \mathrm{~J}$, the contact force decreased abruptly from $\sim 3.5 \mathrm{kN}$ to $\sim 2.5 \mathrm{kN}$ (at time of $\sim 4 \mathrm{~ms}$ ), as shown in Fig. 6(c). The sudden drop of the impact force is attributed to the occurrence of the fibre damage in yarns. At this impact-energy level, the peak load was similar to that at impact energy of $6 \mathrm{~J}$. Here, the internal delamination critically degraded the bending stiffness of the plate, which, in turn, reduced the contact force [14]. In the numerical models based on shell elements (SCZ and ECZ), the impact force took a longer time to degrade to zero in the rebound phase when compared to experiments. The load deviation during the unloading phase is probably due to an underestimation of the impact-induced damage [14]. However, the ECZ3D model provided clearly improved predictions. The first drop in the impact force, $F_{d}$, was captured in the ECZ3D model, which was due to a large growth of delamination in the structure. Overall, the trend of FE results agrees well with the experimental data with the peak loads being predicted accurately.

Energy-absorption behaviour of the braided composite at different impact energies are shown in Fig. 7. The maximum energy level is the strain energy that equals the initial kinetic energy of the impactor. The strain energy was partly converted back to kinetic energy due to rebound of the impactor. The rest energy was progressively dissipated by the composite plate. The final constant energy values shown in the 

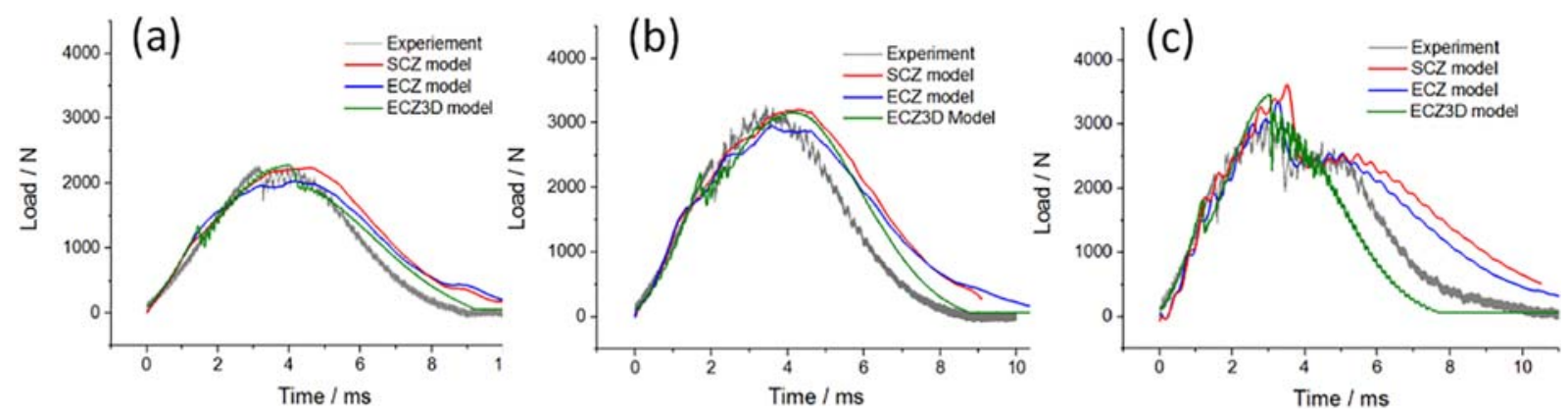

Fig. 6. Load-time response of braided composite plate under variable impact energies: (a) $3 \mathrm{~J}$; (b) $6 \mathrm{~J}$; and (c) 9 J.

graphs are equal to the absorbed energy. The FE simulation results captured the total strain energy reasonably well. However, some variations observed were in the predicted final absorbed energy after impact. According to Fig. 7, the responses obtained with the SCZ and ECZ models were nearly the same; both being smaller than experimental observations. Therefore, the FE models with shell elements underestimated the energy-dissipation capacity of the composite because of their inability to account for the through-thickness damage. It was noted that the absorbed energy predicted with the ECZ3D model was close to the experimental observations at all the investigated impact-energy levels.

The fraction of energy absorbed during the impact process is shown in Fig. 8. The energy-absorption capacity is related to the extent of internal damage and energy dissipation by each damage mode. When the impact energy increased, BVID became severe in the specimen. The fraction of the final absorbed energy, therefore, increased from $50 \%$ at impact energy of $3 \mathrm{~J}$ to $77.8 \%$ at $9 \mathrm{~J}$. The error between the predicted absorbed energy and its experimental value was within $15 \%$ when the 3D FE model was used. The energy dissipation is attributed to BVID inside the composite for the impact energy below $6 \mathrm{~J}$. At impact energy of $9 \mathrm{~J}$, plastic deformation is expected to occur in the composite (which should account for a small fraction of energy spent). Due to the difficulty in obtaining accurate values for fracture energy of each damage mode and the assumptions used in the simulations, the final absorbed energy obtained with FE simulations was lower than that in the experiments.

The experimentally and numerically obtained results were compared with those from the analytical spring-mass model to identify the bending and membrane effects. As shown in Fig. 9, load-deflection curves of the impacted composite specimen were plotted starting from its undeformed state to the maximum-deflection state. For the impact energies $3 \mathrm{~J}$ and $6 \mathrm{~J}$, the load-deflection curves agree well with the experimental observations at the loading portion, indicating a quasistatic behaviour of the braided-composite plate under a low-energy impact. Specifically, the analytical load threshold for delamination onset was predicted at $1776.7 \mathrm{~N}$, slightly lower than in the experiments, while the analytically calculated peak loads (2267.8 $\mathrm{N}$ at $3 \mathrm{~J}$ impact and $3262.9 \mathrm{~N}$ at $6 \mathrm{~J}$ impact) corresponded with the experimental measurement. After delamination initiation, the analytical solutions provided upper and lower bounds: the upper bound (the dashed line in Fig. 9) was obtained considering no interface damage, while the lower bound (the solid line) indicates the bending stiffness gradually reduced due to delamination. The dashed lines in Fig. 9 present a significant membrane effect if there is no delamination. It is obvious that the onset of delamination caused strong oscillations around the average value, which was similar to the analytically predicted magnitude. Additionally, the numerical results from the ECZ3D model were also fairly consistent with those from the experiments and the analytical model.

Although analytical modelling is a simple and effective method to assess global parameters such as bending stiffness, the critical shear load and the peak load for the response of braided composite to impact loading, the analytical results depend strongly on the used assumptions. By contrast, FE modelling has its advantages in obtaining spatial distributions of parameters (i.e. stresses and strains) in cases of complicated geometries and varying loading conditions. It is also widely employed to predict delamination, one of typical damage modes in layered composite materials. Herein, the predicted delamination area at the interface of braided composite is shown in Fig. 10. Additionally, delamination can be observed clearly in Micro-CT scan images at the cross-section plane and denoted as a darker zone in Fig. 10 (translucency was applied to plies in order to visualize all the damaged interfaces). It is obvious that the damage contours are mainly along the longitudinal direction. This is consistent with the experimental observations that matrix cracks initiated around the impact area and propagated along the braiding angle of yarns in the longitudinal direction. The area of delamination increased with the impact energy. According to Fig. 10, although the dumbbell shape of the delamination area was captured with the FE simulations, the delamination area was underestimated when the SCZ model was applied. However, in the ECZ and ECZ3D models, the predicted delamination areas agreed well with the images acquired from CT-scan. The damage contours were symmetrical, with an unseparated area in the middle, which was the contact region between the impactor and the specimen.

Quantitative comparisons between numerical and experimental results are presented in Fig. 11, where delamination areas, measured based on image analysis, are plotted as a function of impact energy. This comparison indicates that ECZ3D model can predict the
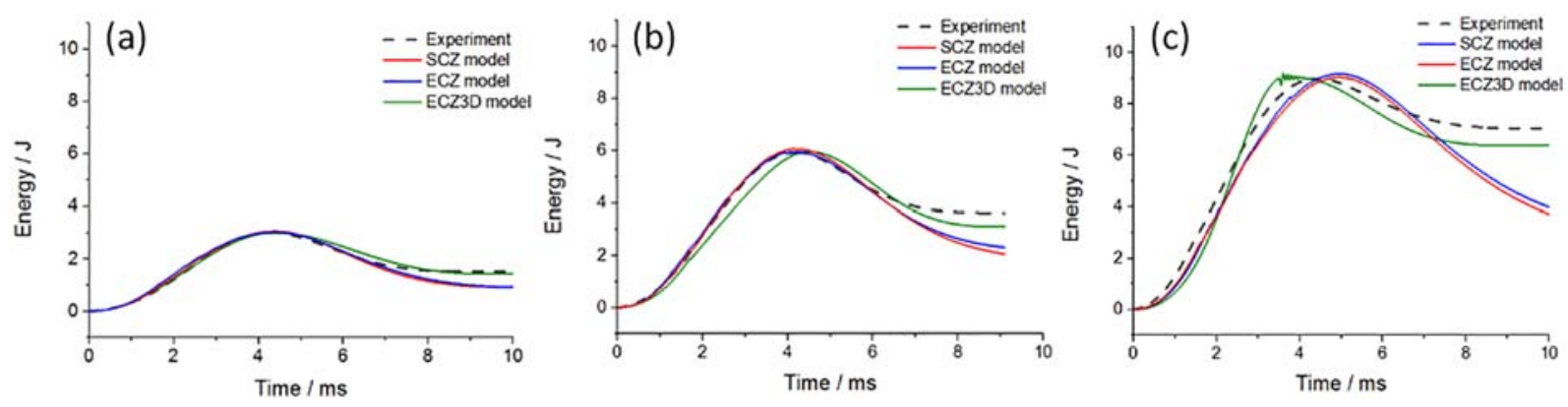

Fig. 7. Energy-time response of braided composite plate under variable impact energies: (a) $3 \mathrm{~J}$; (b) $6 \mathrm{~J}$; and (c) $9 \mathrm{~J}$. 


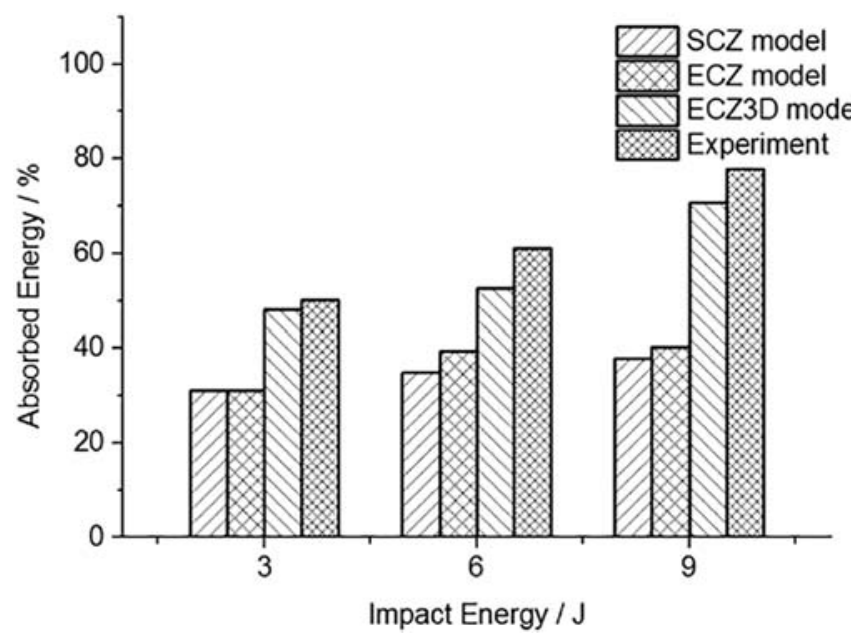

Fig. 8. Fraction of energy absorbed during impact obtained by numerical and experimental approaches.

delamination area most accurately. On the other hand, with the SCZ model, obviously smaller delamination areas were predicted because of two possible reasons. First, surface-based cohesive interactions have limitations if the cohesive connection is subjected to relative in-plane sliding ( shear Mode II or III) [36]. Such interface failure mode is common for low-velocity impacts, in which interface failure mainly results from bending-induced shears stresses around the impact area and friction after debonding [9,31]. Hou et al. [3] also suggested that for delamination constrained by compressive through-thickness stress, a smaller damage was predicted. Second, in the element-based approach, the failed elements were removed from the model. On the contrary, surface-based cohesive interactions may re-bond when contact is established even after interface debonding, thus reducing a visually observed delamination area $[35,36]$.

Based on the results above, both the surface- and element-based cohesive zone models can be applied at interfaces between composite layers. The global responses, including load and energy histories, were effectively obtained from these two approaches. The use of the SCZ model is often preferred due to its simplicity and lower computational cost. The ECZ model was able to deliver more information with regard to the geometry and the evolution of interface damage with time. The ECZ3D model incorporating a VUMAT subroutine provided more precise results in terms of delamination areas and energy-dissipation capacity, though with a higher computational cost.

The obtained morphology of damage in the braided composite after the impact is presented in Fig. 12. At the impact energy of $3 \mathrm{~J}$, no obvious damage can be seen since all the energy dissipation was due to BVID. However, from Fig. 12(b), micro-cracks parallel to fibre filaments and fibre breakage were observed in yarns. When the impact energy increases to 9J, macro cracks could be found on the surface of the composite plate, indicating inter-yarn debonding and matrix failure. Therefore, besides delamination, cracks in matrix and fibre breakage were important damage modes absorbing impact energy.

Matrix damage may be predicted with the ECZ3D model thanks to different failure modes defined in the Hashin's 3D damage criteria. Contours of the tensile failure $\left(d_{m t}\right)$ inside the matrix from both sides of the composite plate are shown in Figs. 12(d) and (e) at the end of the damage propagation period. The matrix cracks were created by flexural inplane stresses so that the matrix tensile failure was the most critical mode for impact damage. Since the spike-shape impactor was used, the damage contour was different from those studies with a hemispheric impactor [16]. There was a flexural zone with a width of the impactor's diameter, with matrix tensile damage occurring mainly along the edge of this zone. Furthermore, the bottom layers of the specimen were subjected to major traction strains resulting from deflection with regard to the impact, leading to matrix cracks in the matrix-rich area $[17,35]$.

Moreover, permanent deformation after impact was captured with the 3D FE model. Fig. 13 shows examples of the cross-section views of the plate after the impact with energy of $9 \mathrm{~J}$. The variables plotted correspond to the residual displacement (from Micro-CT image), von-Mises stress and transverse damage variable (from the ECZ3D model). As shown in Fig. 13, the centre of the mentioned flexural zone has a residual displacement of $0.383 \mathrm{~mm}$ after the $9 \mathrm{~J}$ impact. The von-Mises stress distribution shows stress concentration around the delamination region. Matrix failure in the thickness direction was also predicted by ECZ3D model.

Based on the experimental and numerical studies, mechanisms of cracks initiation and propagation inside the braided composite were investigated. Micro-CT images in Fig. 14 indicate that at the initial stage of impact, the impact load caused matrix cracking and then delamination. In the braided composite, there were some relative matrix-rich zones because of the pattern of interlacing yarns. When the composite plate bends, micro-voids are easily created in such zones before the onset of cracks. With the impact energy increasing, the laminate bending caused differences in shear stresses between the adjacent layers.

These shear stresses caused propagation of delamination along the yarn surface [37,38]; Fig. 14(b) shows that inter-yarn cracks were formed after the increase in delamination. It is noted that the interyarn cracks could be blocked by the interlacing of yarns, contributing to maintenance of the structure integrity of the braided composite. Yarn-debonding was another mechanism of energy absorption, besides delamination and matrix damage. Under higher impact energy, normal stress through the thickness direction resulted in server matrix damage concentrated in the area directly under the impactor's edges. Moreover, when inter-yarn cracks grew to the front surface, macro cracks were observed on the composite specimen (Fig. 12(c)). According to discussions
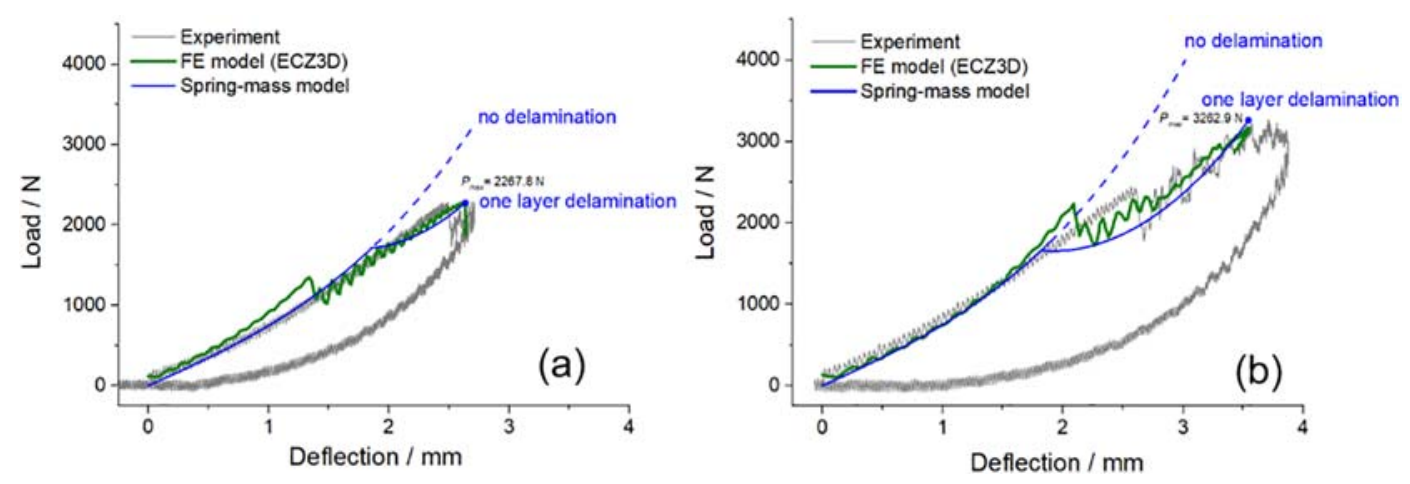

Fig. 9. Comparison of load-deflection curves obtained from experimental tests with analytical data and ECZ3D FE simulations for $3 \mathrm{~J}$ (a) and $6 \mathrm{~J}$ (b) impacts. 

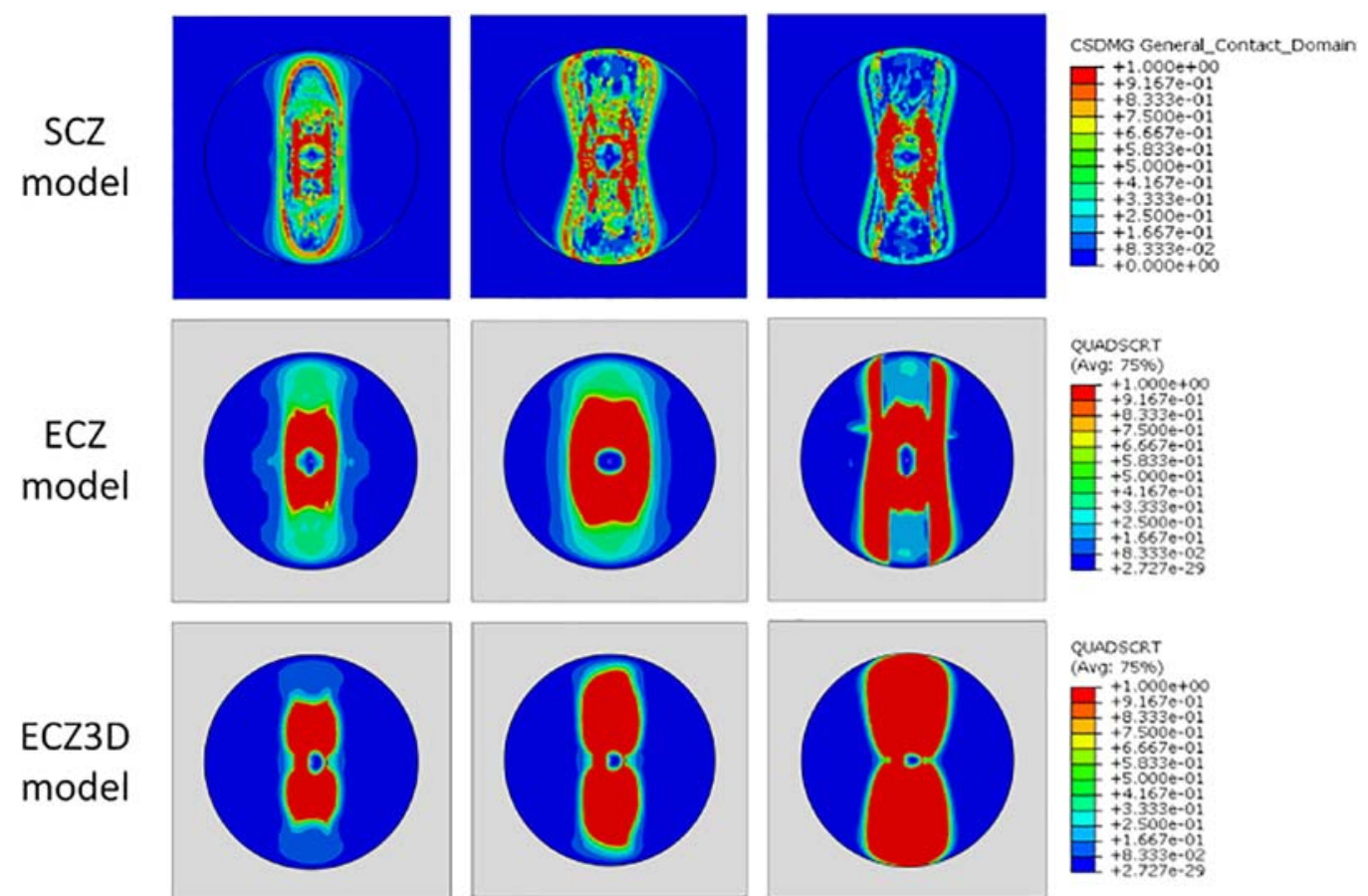

QUADSCRT
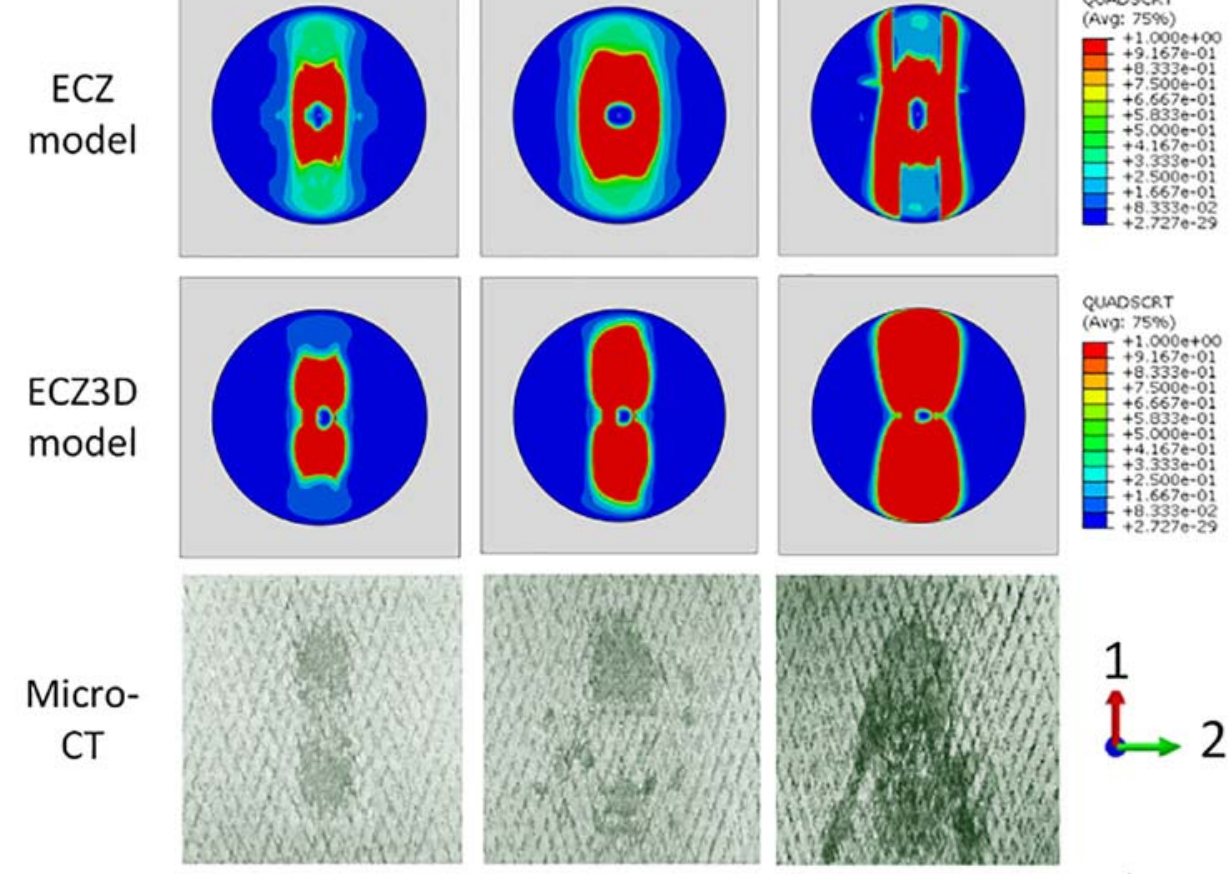

Impact Energy 3 J

$6 \mathrm{~J}$

9 J

Fig. 10. Interface delamination of braided composite plate modelled with surface-based and element-based cohesive models together with CT scans for various impact energies.

above, a schematic of potential propagation paths of delamination and inter-yarn cracks is showed in Fig. 14(d). In summary, the braided structure of yarns not only increases the impact resistance of composites, but also improves energy absorption by inducing inter-yarn cracks during impact. From this point of view, braided composites are promising candidates for sports protection.

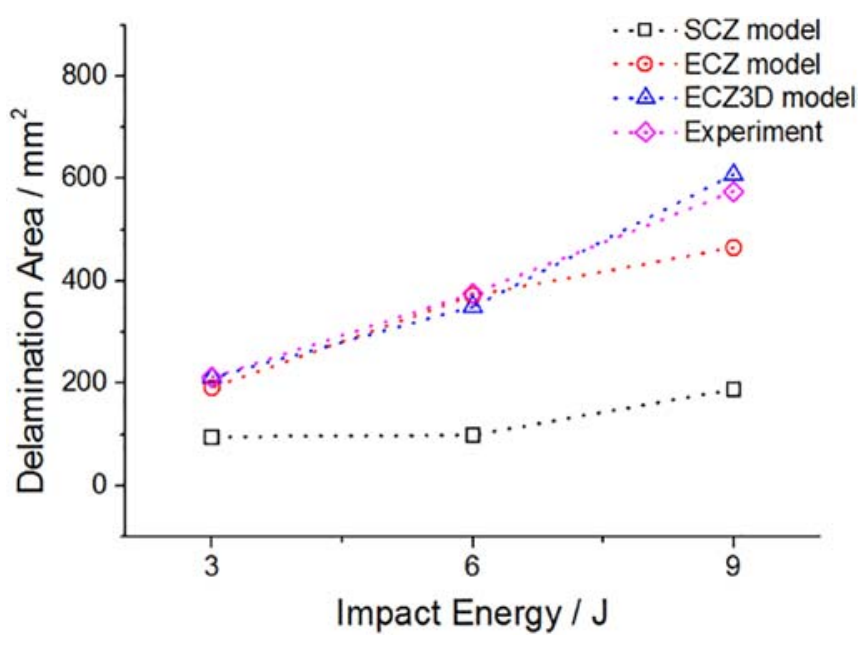

Fig. 11. Evolution of delamination in braided composite plate with impact energy.
Furthermore, as a case study, the predicted responses of the shinguard specimens in the impact-attenuation test were compared with the experimental data; Fig. 15 shows comparisons for evolution of the normalised acceleration with time. The maximum acceleration, $G_{\max }$, was around $49.79 \pm 1.60$ and $63.56 \pm 3.57$ of gravity for impact energy of $4 \mathrm{~J}$ and $6 \mathrm{~J}$, respectively with the respective impact attenuation factor, $\eta$, around 2.63 and 2.7. Apparently, the numerical results agree well with the experimental data in terms of both the peak acceleration value and the duration time.

The impact-induced delamination area can also be evaluated with the FE method, as shown in Fig. 16. The shapes of delamination are clearly influenced by architecture of braided patterns, specifically bradding angles. For the braiding angle of $25^{\circ}$, delamination initiates symmetrically around the impact point and propagates mainly along the longitudinal direction due to the difference in stiffness between longitudinal and transverse directions. Besides interface damage, the impact energy was also dissipated by internal damage of the composite plate. The main damage mode for composite layers was matrix failure in tension.

Hence, to achieve better energy absorption performance in sports applications, geometrical structures, material properties and braiding parameters should be considered and optimised. The modelling capability presented in this study will be helpful to provide guidelines for product design. For instance, a real shin-guard structure can be modelled including directly its main components - the composite layer and the foam liner. Then, the braiding angle and the structural shape could be optimised employing meso- and macro-scale geometries, thanks to the multi-scale modelling hierarchy. 

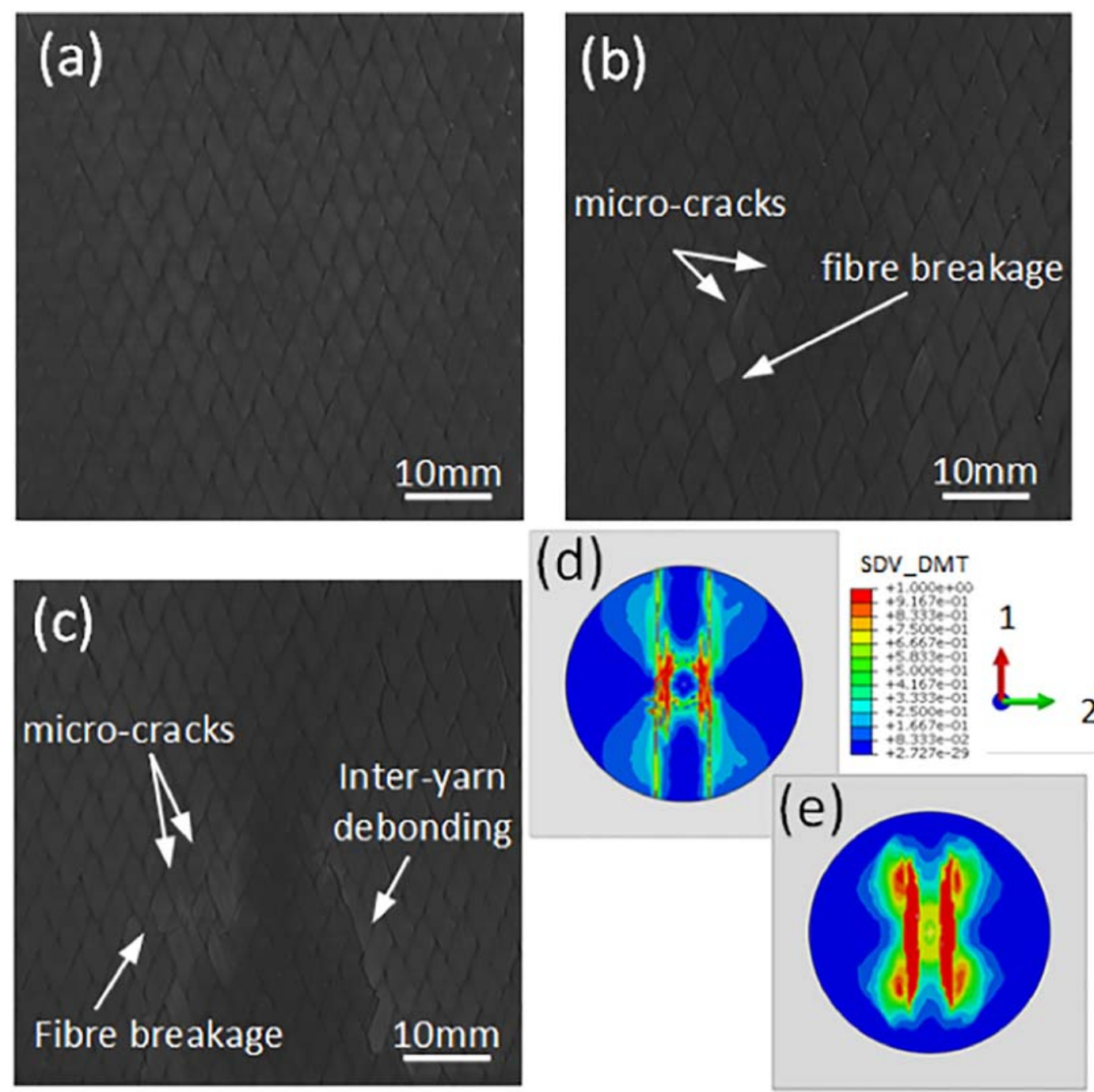

Fig. 12. Micro CT-scan surface morphology of composite after impact with energy of (a) $3 \mathrm{~J}$, (b) $6 \mathrm{~J}$ and (c) $9 \mathrm{~J}$. Numerically predicted matrix-damage contours in composite plate after $9 \mathrm{~J}$ impact: (d) front view; (e) back view.

(a)

(b)

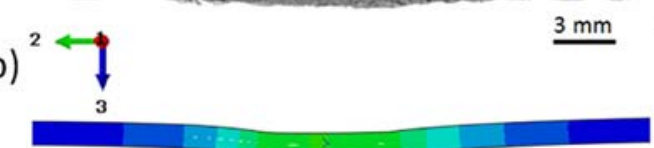

(c)

(d)

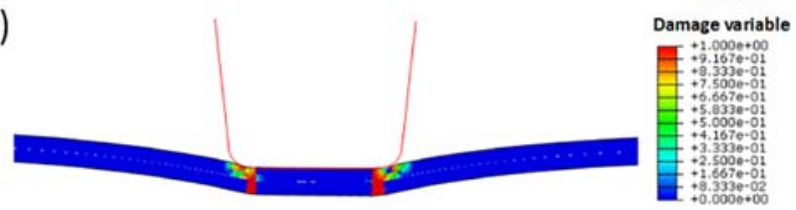

Fig. 13. Cross-section view of braided composite plate with impact energy of $9 \mathrm{~J}$ : (a) Micro-CT scan morphology of permanent deformation; (b) residual displacement contours; (c) von Mises stress distribution; and (d) matrix failure in thickness direction predicted by ECZ3D model.

\section{Conclusions}

The response of the braided composite to low-velocity impacts was investigated both experimentally and with FE simulations; impact
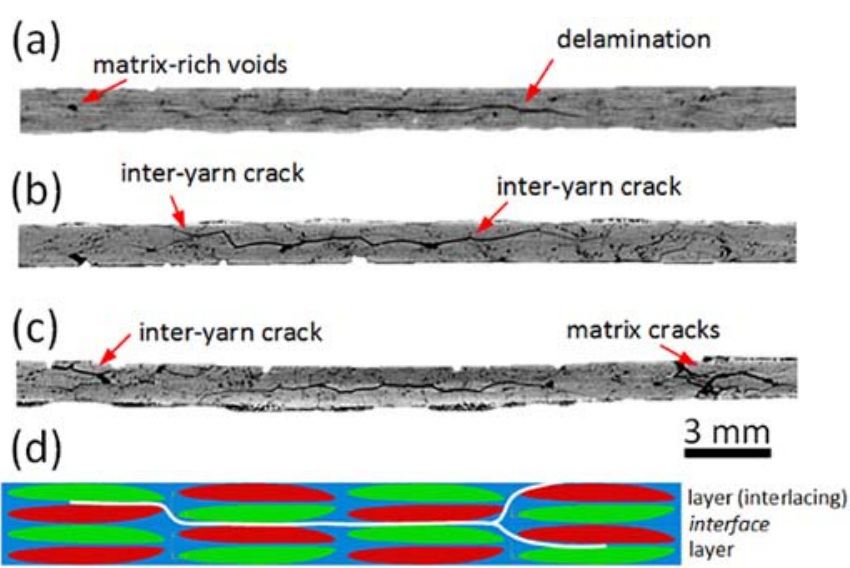

Fig. 14. Delamination and cracks in Micro-CT scan images: cross-section of braided composite plate after impact with (a) $3 \mathrm{~J}$, (b) $6 \mathrm{~J}$ and (c) $9 \mathrm{~J}$; (d) illustration of crack propagation. 

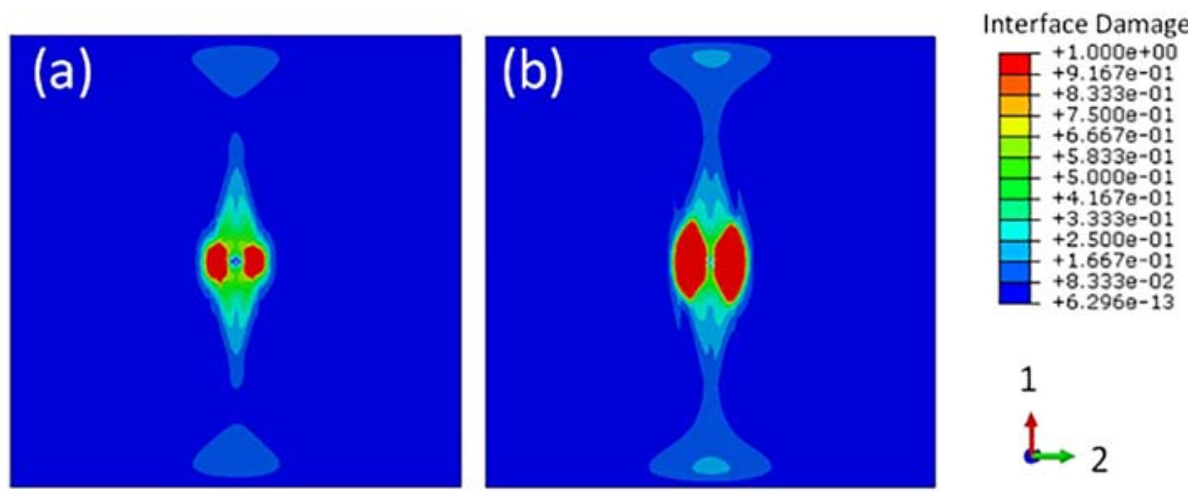

Fig. 16. Delamination in composite shell of shin guard with respect to impact energy: (a) $4 \mathrm{~J}$; (b) $6 \mathrm{~J}$.

[4] M. Alemi-Ardakani, A.S. Milani, S. Yannacopoulos, H. Borazghi, A rapid approach for
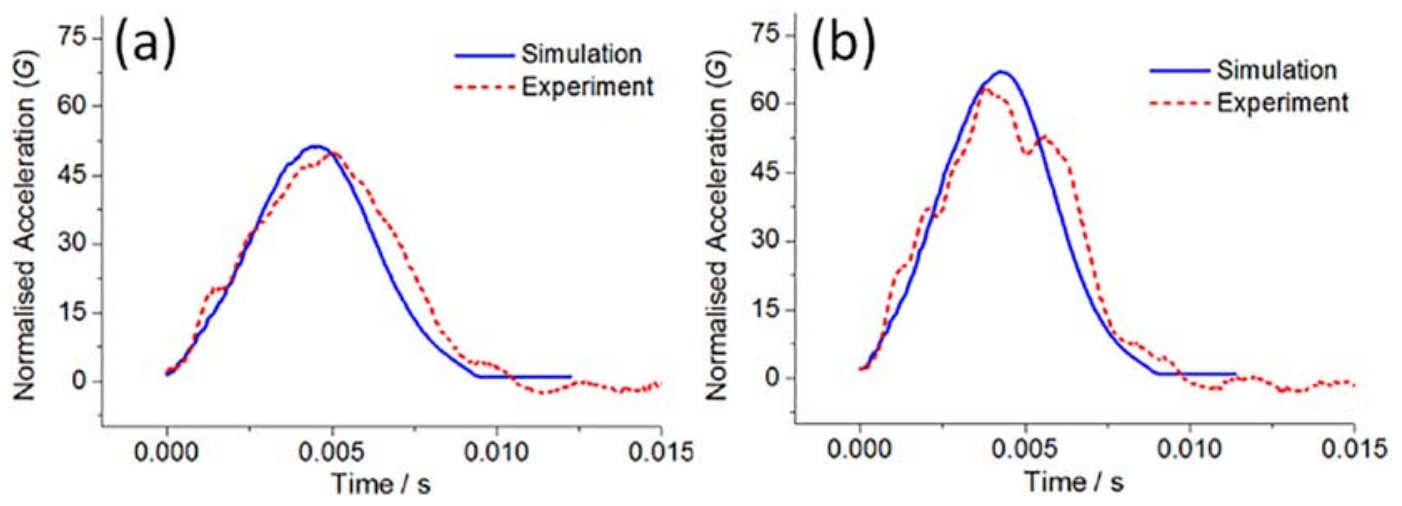

Fig. 15. Normalised acceleration-time diagrams obtained in impact attenuation tests and numerical simulations under $4 \mathrm{~J}$ (a) and $6 \mathrm{~J}$ (b) impacts.

energy levels ranged from $3 \mathrm{~J}$ to $9 \mathrm{~J}$. The present work offers reasonable modelling capabilities for low-velocity impacts. The simulated results were verified with the original experimental data and analytical models. The obtained results show that both surface- and element-based cohesive zone models can be applied as interface between composite layers. The global responses are effectively obtained without much difference from these two approaches. When shell elements were used as composite plies, the absorbed energy was underestimated. The ECZ model with 3D stress elements provided more precise results for the delamination areas and energy dissipation capacity, at a higher computational cost. The main energy dissipation mechanisms of braided composites under low-velocity impact were delamination, matrix failure and, uniquely for the braided composite, inter-yarn debonding. The modelling approach presented in this study is able to enhance product design for sports applications by predicting energy absorption of the braided composites and impact damage in products. As a case study, a shin-guard structure was successfully modelled with the developed computational scheme. The predicted impact-attenuation performance was compared with testing data, demonstrating a good agreement. By changing structural and materials parameters, varying from micro- to macro-scale models, energy absorption and the impact-attenuation factor of the shin-guard can be obtained for further studies.

\section{References}

[1] C.S. Lopes, O. Seresta, Y. Coquet, Z. Gürdal, P.P. Camanho, B. Thuis, Low-velocity impact damage on dispersed stacking sequence laminates. Part I: experiments, Compos. Sci. Technol. 69 (2009) 926-936.

[2] M. Schwab, M. Todt, M. Wolfahrt, H.E. Pettermann, Failure mechanism based modelling of impact on fabric reinforced composite laminates based on shell elements, Compos. Sci. Technol. 128 (2016) 131-137.

[3] J.P. Hou, N. Petrinic, C. Ruiz, S.R. Hallett, Prediction of impact damage in composite plates, Compos. Sci. Technol. 60 (2000) 273-281. predication and discrete lay-up optimization of glass fiber/polypropylene composite laminates under impact, Int. J. Impact Eng. 84 (2015) 134-144.

[5] S. Abrate, Modeling of impacts on composite structures, Compos. Struct. 51 (2001) 129-138.

[6] M.S.H. Fatt, K.S. Park, Dynamic models for low-velocity impact damage of composite sandwich panels-part A: deformation, Compos. Struct. 52 (2001) 335-351.

[7] R. Olsson, Analytical prediction of large mass impact damage in composite laminates, Compos. A: Appl. Sci. Manuf. 32 (2001) 1207-1215.

[8] C.S. Lopes, P.P. Camanho, Z. Gürdal, P. Maimí, E.V. González, Low-velocity impact damage on dispersed stacking sequence laminates. Part II: numerical simulations, Compos. Sci. Technol. 69 (2009) 937-947.

[9] A. Riccio, F. Caputo, G. Di Felice, S. Saputo, C. Toscano, V. Lopresto, A joint numericalexperimental study on impact induced intra-laminar and inter-laminar damage in laminated composites, Appl. Compos. Mater. 23 (2016) 219-237.

[10] S. Long, X. Yao, X. Zhang, Delamination prediction in composite laminates under low-velocity impact, Compos. Struct. 132 (2015) 290-298.

[11] A. Qiu, K. Fu, W. Lin, C. Zhao, Y. Tang, Modelling low-speed drop-weight impact on composite laminates, Mater. Des. 60 (2014) 520-531.

[12] J. Zhang, X. Zhang, Simulating low-velocity impact induced delamination in composites by a quasi-static load model with surface-based cohesive contact, Compos. Struct. 125 (2015) 51-57.

[13] D. Feng, F. Aymerich, Finite element modelling of damage induced by low-velocity impact on composite laminates, Compos. Struct. 108 (2014) 161-171.

[14] E.H. Kim, M.S. Rim, I. Lee, T.K. Hwang, Composite damage model based on continuum damage mechanics and low velocity impact analysis of composite plates, Compos. Struct. 95 (2013) 123-134.

[15] H. Singh, P. Mahajan, Modeling damage induced plasticity for low velocity impact simulation of three dimensional fiber reinforced composite, Compos. Struct. 131 (2015) 290-303.

[16] R.K. Gideon, F. Zhang, L. Wu, B. Sun, B. Gu, Damage behaviors of woven basaltunsaturated polyester laminates under low-velocity impact, J. Compos. Mater. 49 (2015) 2103-2118

[17] W. Wang, X. Wan, J. Zhou, M. Zhao, Y. Li, S. Shang, X. Gao, Damage and failure of a laminated carbon fiber reinforced composite under low velocity impact, J. Aero. Eng. 27 (2014) 308-317.

[18] ASTM F355-16. Standard Test Method for Impact Attenuation of Playing Surface Systems, Other Protective Sport Systems, and Materials Used for Athletics, Recreation and Play. 
[19] ASTM F1631-95. Standard Test Method for Impact Attenuation Properties of Body Padding and Protective Wear for the Sport of Fencing.

[20] J. Llorca, C. González, J.M. Molina-Aldareguía, J. Segurado, R. Seltzer, F. Sket, L.P. Canal, Multiscale modeling of composite materials: a roadmap towards virtual testing, Adv. Mater. 23 (2011) 5130-5147.

[21] X. Ji, C. Wang, B.P. Francis, E.M.S. Chia, L.X. Zheng, J.L. Yang, Z. Chen, Mechanical and interfacial properties characterisation of single carbon fibres for composite applications, Exp. Mech. (2015) 1057-1065.

[22] C. Wang, Y.C. Zhong, B.P. Adaikalaraj, X.B. Ji, A. Roy, V.V. Silberschmidt, Z. Chen, Strength prediction for bi-axial braided composites by a multi-scale modelling approach, J. Mater. Sci. 51 (2016) 6002-6018.

[23] Z. Hashin, Fatigue failure criteria for unidirectional fiber composites, J. Appl. Mech. 48 (1981) 846

[24] I. Lapczyk, J. Hurtado, Progressive damage modeling in fiber-reinforced materials, Compos. A: Appl. Sci. Manuf. 38 (2007) 2333-2341.

[25] F. Guo-dong, L. Jun, W. Bao-lai, Progressive damage and nonlinear analysis of 3D four-directional braided composites under unidirectional tension, Compos. Struct. 89 (2009) 126-133.

[26] P. Maimí, P.P. Camanho, J. Mayugo, C.G. Dávila, A continuum damage model for composite laminates: part II - computational implementation and validation, Mech. Mater. 39 (2007) 909-919.

[27] H. Kang, Z. Shan, Y. Zang, F. Liu, Progressive damage analysis and strength properties of fiber-bar composites reinforced by three-dimensional weaving under uniaxial tension, Compos. Struct. 141 (2016) 264-281.

[28] S. Murakami, Mechanical modeling of material damage, J. Appl. Mech. 55 (1988) 280

[29] P.P. Camamho, C.G. Dávila, M.F. Moura, Numerical simulation of mixed-mode progressive delamination in composite materials, J. Compos. Mater. 37 (2003) 1415-1438.
[30] M.L. Benzeggagh, M. Kenane, Measurement of mixed-mode delamination fracture toughness of unidirectional glass/epoxy composites with mixed-mode bending apparatus, Compos. Sci. Technol. 56 (1996) 439-449.

[31] E.V. González, P. Maimí, P.P. Camanho, A. Turon, J. Mayugo, Simulation of dropweight impact and compression after impact tests on composite laminates, Compos. Struct. 94 (2012) 3364-3378.

[32] Y. Shi, C. Pinna, C. Soutis, Modelling impact damage in composite laminates: a simulation of intra- and inter-laminar cracking, Compos. Struct. 114 (2014) 10-19.

[33] M.T. Petre, E. Ahmet, P.R. Cavanagh, Determination of elastomeric foam parameters for simulations of complex loading, Comput. Methods Biomech. Biomed. Eng. 9 (2006) 231-242.

[34] C.G. Fontanella, A. Forestiero, E.L. Carniel, A.N. Natali, Analysis of heel pad tissues mechanics at the heel strike in bare and shod conditions, Med. Eng. Phys. 35 (2013) 441-447.

[35] R.P. Lemanle, C. Garnier O. Pantalé, Finite element simulation of low velocity impact damage on an aeronautical carbon composite structure, Appl. Compos. Mater. (2016) 1-14.

[36] Dassault Systemes Simulia Corp., Providence, RI, USA, Abaqus Analysis User's Guide, Version 6.14, 2014

[37] J. Bienias, P. Jakubczak, K. Dadej, Low-velocity impact resistance of aluminium glass laminates - experimental and numerical investigation, Compos. Struct. 152 (2016) 339-348.

[38] A. Elias, F. Laurin, M. Kaminski, L. Gornet, Experimental and numerical investigation of low energy/velocity impact damage generated in 3D woven composite with polymer matrix, Compos. Struct. 159 (2017) 228-239. 